\title{
Author Correction: lon exchange in atomically thin clays and micas
}

Yi-Chao Zou (1), Lucas Mogg, Nick Clark (D), Cihan Bacaksiz, Slavisa Milovanovic (1), Vishnu Sreepal, Guang-Ping Hao (D), Yi-Chi Wang (D), David G. Hopkinson (1), Roman Gorbachev (D), Samuel Shaw, Kostya S. Novoselov (D),

Rahul Raveendran-Nair (D), Francois M. Peeters, Marcelo Lozada-Hidalgo (D) and Sarah J. Haigh (D)

Correction to: Nature Materials https://doi.org/10.1038/s41563-021-01072-6, published online 26 August 2021.

In the version of this Article initially published, the author Slavisa Milovanovic's name was misspelt as "Milanovic."

The error has been corrected in the online version of the Article.

Published online: 21 September 2021

https://doi.org/10.1038/s41563-021-01134-9

(c) The Author(s), under exclusive licence to Springer Nature Limited 2021 